as follows: "Thirdly. The disappearance of the hectic and the complete recovery without a bad symptom, attrihutable, in my opinion, to the thorough extirpation of the diseased structures." The pulmonary affection, I regret to say, recurred in this case and carried him off a few yeary ago.

Elbow jont. - In 1876 I excised the elbow-joint in an Indian named $W m . B$, aged sixteen, a native of Terra del Fueno, when stationed in the Falkland Islands. The boy belonged to the South American Missionary Station, and was sent to me by its local principal; he was highly scrofulous, and the disease of the joint and neighbouring bones was so extensive that I feared for a long time amputation would have been required, an opinion which had been formed some time previously by the surgeon of a Chilian hospital. He had decided pulmonary complications; there was dulness beneath the clavicles, elevated temperature, prolongrd expiration, crackling, and a most barassing cougb, all of which entirely disappeared in a few months after the operation. Amongst the compatriots of this youth phthisis occurring in a scrofulous subject runs a very short course. This was exemplified in the case of a comrade of the patient, who had a scrofulous elbow also. He came to the Falkland Islands for advice, and left on the day I arrived, but his elbow was shown to me on his way to embark; it was enlarged, doughy, and semi-fluctuating In less than three months he died from tuberculosis. Wm. $\mathrm{B}-$ is still in the land of the living, but has lately become the suhject of some constitutional disease, the nature of which $I$ have not been made aware of, but I fear it is phthisis.

Hip.joint: Amyloid, Scrofula.-In 1877 I excised the hip for a young woman, Mrs. B _ a , aged nineteen, residing in Stanley, Falkland Islands. Her system was markedly scrofulous, and there was reason to apprebend that amyloid changes were in progress. Two large saucerfuls of pus were discharged daily from the hip and its vicinity for many months. Hectic was confirmed and of long standing. The sleep was unrefreshing; delirium occurred towards norning, and she was not always collected by day; aph thæ were present on the tonuue and lips, and the debility was so great she could not move the sound leg. The urine had become albuminons, and had a dirty tobacco-juice appearance. These symptoms entirely passed away very soon aiter the operation, and in eighteen months she was fat, strong, and rosy. I regret to say I have recently been apprised of her death, but not of its cause. I am, Sir, yours truly,

H.M Dockyard, Portsmouth, Nov. 12th, 1881.

$$
\text { J. MulvaNy, M.D., F.M.S., }
$$
Staff-Surgeon, R.N.

\section{AMBULANCES IN CIVIL PRACTICE.}

\section{To the Editor of THE LANCET.}

SIR,-As in your excellent annotation of Novemher 5th, on the occasion of Mr. Harrison's address at Liverpool on the above subject, you observe that the present condition of London and of other large towns is, in the defects or deficiency of such appliances, "hardly short of a disgrace to our civilisation," I take the liberty of showing that, in this respect, as in some others, Ramsgate has rather set an example that larger and more wealthy towns might follow. In its centre, yet sufficiently screened from observation as well as remote from dwelling houses, are, under one roof, a disinfecting chamber, a mortuary, and a post-mortem chamber, the two latter supplied with every convenience, and with light, air, gas, and water. Contiguous to all is a separate shed for containing a mortuary vehicle, a small carriage of varnished wood, drawn hy one horse, not having the alpearance of a conveyance for the dead, and constructed to hold two shells, each lined with coppered tin. These are for carring to the mortuary either corpses cast on the shore, or the bodies of those who have died in crowded houses of any infectious disease. Ramsgate contributes the largest share to the support of an infectious diseases hospital nearly a nile from the town, and has had bullt an ambulance carriage which, I think, meets the very requirements on which you have so properly insisted. It is like an omuibus, rather low, with a wide door behind with glass and shutters in it, with thick glass on the sides, and thoroughly ventilated both at each end and the top. Within the seat is narrow on one side for a nurse or parents to sit; on the other side it is wide enough and ling enough for either two children or an adult to lie stretched out at full length, whilst it holds three patients semi-recumbent, with the necessary attendants on them. There are comfortable leather-covered cushions (disinfected easily) and two full-sized railway foot-warmers. The vehicle may be drawn by two horses or by one, with a driving box for two, aud a boot beneath for whatever may be thought expedient. It is on easy springs, of varnished birch, and lonks like a small private omnibus. It is used by Broadstairs, Margate, and the rural district, and has proved a source of comfort and safety, to children most especially, transported perhaps from home to hospital over rough or ice-bound roads in the depth of a winter's night. A cari iage like this might obviously be modified so as to be as suitable for accidents as for zymotic diseases,

St. Lawrence, Ramsgate, Nov. 1881. I am, Sir, yours, \&c., HENRY JAMES JOHNSTONE.

\section{PROFESSOR VIRCHOW'S TESTIMONIAL. To the Editor of THE LANCET.}

SIR,-I beg leave to acknowledge the receipt of the undermentioned sums since my letter to you of last week. The total amount of subscriptions I have received is $£ 996 \mathrm{~s}$.; of which all but three guineas has been forwarded to Professor Küster.

$$
\begin{array}{llllllllll}
\text { Dr. Southey } & \ldots & \ldots & \ldots & \ldots & \ldots & \ldots & £ 1 & 1 & 0 \\
\text { Dr. Barratt } & \ldots & \ldots & \ldots & \ldots & \ldots & \ldots & 1 & 1 & 0 \\
\text { Dr. Beddoe } & \ldots & \ldots & \ldots & \ldots & \ldots & \ldots & 1 & 1 & 0 \\
\text { J. Croft, Esq... } & \ldots & \ldots & \ldots & \ldots & \ldots & 1 & 1 & 0
\end{array}
$$

I am, Sir, your obedient servant,

$$
\text { old Burlington-street, Nov. 21th, } 1881 \text {. J. S. BRISTowE. }
$$

\section{THE ST. JOHN AMBULANCE ASSOCIATION. To the Editor of THE LANCET.}

SIR,-Major Duncan is, without doubt, a most hardworking philanthropist, but that is no reason why the St. John Ambulance Association should not be open to criticism. On perusing the programme $I$ find that lectures on anatomy and physiology are given to ladies, and that it is only after they have gained certificates in these classes they are entitled to attend a second course of lectures in bygiene and nursing. I for one think that the smattering knowledge of anatomy gained in a short course of lectures would prove a dangerous thing. But to a practical course of lectures on the mauagement of the sick, and a supplementary course on healthy bouses, there could be no possible objection. Remember, Sir, that I am picking out the weak places in the society's programme. The classes for instructing public bodies of men in the art of giving aid to the iujured deserve the utmost praise. If ladies want a hobby to ride, why should they not unite to try to improve the donkeys of the poor in our large towns; see that the ragged urchins at our schuols have proper clothing; and help medical men in providing the necessitous sick with nourishment? I am, Sir, yours obediently,

\section{A COUNTRY PRACTITIONER.}

N.B.-I have not the names of the gentlemen forming the committees on the various centres by me now, but I examined them a few weeks since. I was particularly struck with the paucity of medical names.

\section{THE TREATMENT OF INFLAMED BURSA PATELLE.}

To the Editor of THE LANCET.

SIR,-On reading Professor Lister's lecture "On the Relation of Micro-organisms to Inflammation," I see that he speaks of the treatment of ehronic inflammation of the bursa patellæ by means of puncture and the introduction of a drainage-tube under antiseptic precautions. The antiseptic dressing he says has to be changed in a day or two, and the tube shortened. At the next dressing, as there is usually only slight oozing, the tube is altogether dispensed with, and in a week or ten da!s the puncture is healed. Now, with all due defereuce to so eminent an authority, I venture to question whether such elaborate precautions are really required. I began puncturing cases of inflamed bursa patellæ 